\title{
Analysis of Image Historical Data of Wooden Sculptures of Su- style Furniture in Ming and Qing Dynasties
}

\author{
Weixia Gao ${ }^{1}$, Yuliang Guo ${ }^{1 *}$ \\ ${ }^{1}$ School of Art and Textile and Clothing, Changshu Institute of Technology, Changshu, Jiangsu, 215500, China
}

\begin{abstract}
In the Ming and Qing dynasties, the image materials of woodcarving furniture in Suzhou area are as important as the actual furniture, which are also valuable material information on the living customs of Suzhou in the Ming and Qing dynasties. From the perspective of imageology, this article analyzes the shape, category, style and other representative works of Su-style furniture's woodcarving visual image, hoping to provide a reference for the research and design of regional furniture carving.
\end{abstract}

\section{Introduction}

Documents, objects and images are the main approaches to the contemporary study of the history of woodcarving techniques of Su-style furniture. Each of them has its own characteristics and complements, providing many of them include the customs of Suzhou, daily life, and traditional skills strong support for us to restore history. Academia has conducted in-depth research and accumulation of the history of painting, an important part of Chinese image history. The mutual study of images and furniture has also been carried out systematically with Dunhuang Studies and Furniture of the Dunhuang Institute of Lanzhou University and Shao Xiaofeng's "Furniture of the Song Dynasty-Research and Image Integration". Although the Ming and Qing dynasty image materials are extensive in subject matter and rich in content, many of them include the customs of Suzhou, daily life, and traditional skills, which show a panoramic view of the social life of Suzhou in the Ming and Qing Dynasties. But the study of Su-style furniture about the image and regionality in the Ming and Qing Dynasties is still blank. Therefore, in the following, through the targeted furniture in the historical data of Ming and Qing images, we will sequentially summarize the woodcarving shapes, patterns, styles, production tools features and connotations of Suzhou urban furniture, Suzhou garden furniture, and Su-style furniture in the image data[1].

\section{Suzhou urban furniture woodcarving in Ming and Qing paintings}

\subsection{Types of urban furniture in the Ming Dynasty's "Map of the River on the Qingming Festival"}

Qiu Ying, one of the four Wumens of the Ming Dynasty, was from Taicang, and later moved to Wuxian. Qiu Ying's imitation of the "Qingming Shanghe River Map" depicts the lively city life and folk customs with the background of Suzhou City in the Ming Dynasty based on the theme of "Qingming Shanghe River". It is a true portrayal of the developed commercial economy in the Jiangnan region, represented by Suzhou after Mingzheng De. Magnificent and luxurious house buildings, row-byhand workshops and urban furniture are everywhere. The urban furniture is mostly placed in the place where the city buys and sells goods intensively or processes products [2]. This article will list the five typical types of urban furniture images, including tables, stools, screens, cabinets, beds, and chairs in Qiuying's Qingming River Picture which listed as shown in Figure 1. 


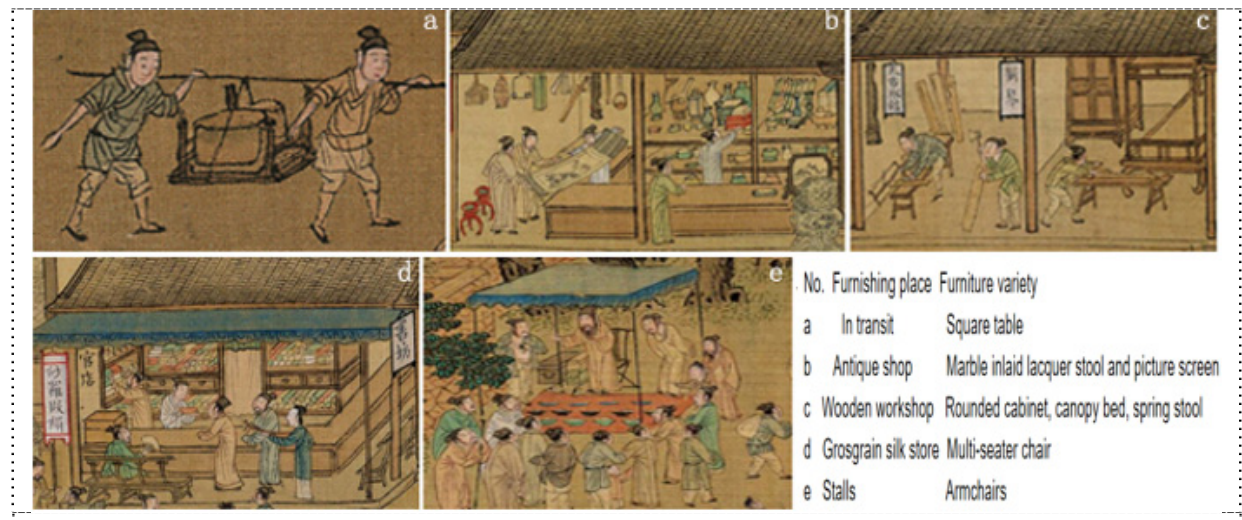

Figure 1. Suzhou urban furniture of "A Picture of the River on the Qingming Festival" in the Ming Dynasty's Qiu Ying edition

\subsection{Types of urban furniture in Ming Dynasty's Suzhou Business Map}

"Suzhou City Well Business Map", an album, thirty-six existing pictures depicting the city well business and customs in Suzhou City in the late Ming Dynasty. There are a large number of well-known furniture in the city. The image of the market furniture is listed, and the prosperous commercial scene of Gusu at that time can be seen slightly.

\subsection{The types of urban furniture in the Qing Dynasty's "Southern Qianlong Tour Picture Volume 6-Stop in Gusu"}

$\mathrm{Xu}$ Yang, author of "Qianlong's South Tour Picture Volume 6-Stop in Gusu", a native of Suzhou, lives in the lanes of the gate of Suzhou. In the sixteenth year of Qing Emperor Qianlong (1751), he was appreciated by the emperor for his painting skills and became a court painter. The volume of "Qianlong's South Tour Picture Volume 6-Stop in Gusu" began in Nanwangting Town, passing by Changzhou County. It depicts the scene of the Emperor Qianlong landing on the boat outside the Suzhou Gate and entering Suzhou City through the Changmen and highlights the bustling scene of Suzhou Yumen. There is only one place in the whole picture that reproduces the appearance of the urban furniture in the Qing Dynasty in detail as shown in Figure 2. That is the wooden shop under the Changmen Bridge. The square corner cabinets and top box cabinets sold in the store are typical types of Qing furniture. The stacked square tables and square stools can also be seen in the pursuit of thick, straight shapes in Qing style furniture. Compared with the tables and stools in Ming Dynasty paintings, the volume has greatly increased.

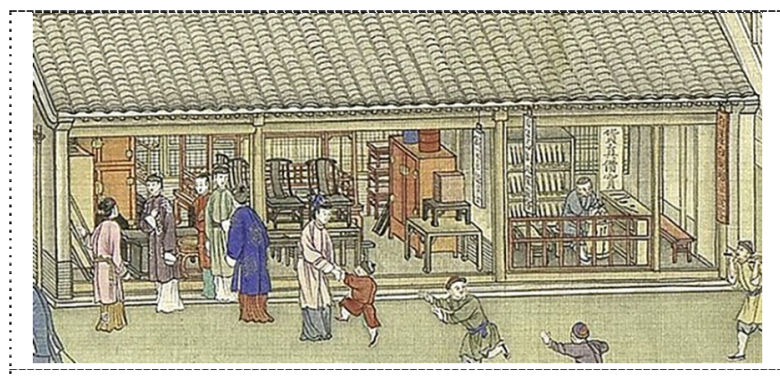

Figure 2. Wooden furniture in the shop of "Qianlong South Tour Picture Book Volume 6-Stop in Gusu"

\subsection{Characteristics of Suzhou urban furniture woodcarving in Ming and Qing Paintings}

The Suzhou urban furniture in Ming and Qing paintings has a complete range of features, with simple shapes and no carvings. This feature is not only related to the group identity of the urban furniture, its cultural literacy, and cheap furniture materials, but also to the type of painting that the urban furniture belongs to. After all, the focus of this kind of social custom painting is not on furniture, so most of the painters simply outline the furniture. From the above paintings, it is not difficult to find that the furniture in Suzhou city painted by Xu Yang in the Qing Dynasty is more delicate than that painted by the Ming Dynasty painter. This should be related to Xu Yang, as a court painter, who was ordered to take the poetic style of imperialism as a picture and used pens to be more detailed and cumbersome.

\section{Suzhou garden furniture woodcarving in Ming and Qing paintings}

During the Ming and Qing Dynasties, Suzhou had a prosperous economy and a wealth of humanities. officials, gentlemen, and nobles competed for garden pavilions in order to live in the garden pavilion and enjoy the mountains and forests. The garden paintings handed down through the ages are a true portrayal of the original history that has been lost in the existing courtyard. The 
furniture in the picture is commonly known as the "house belly" of garden architecture. It has the functions of daily living and recreation, and it is also a carrier of the cultural connotation and mood of Suzhou gardens. The garden furniture in the picture is mainly Su-style furniture in the Ming and Qing Dynasties, with various types, exquisite materials, exquisite workmanship and elegant style.

The paintings of Suzhou garden furniture in the paintings from the middle to late Ming Dynasty to early Qing Dynasty are simple in style and less carved. This type of painting focuses on the depiction of the garden architectural environment, and the furnishings need only be outlined simply. On the other hand, it is also closely related to the secluded life pursuit of Suzhou garden masters and elegant house interest at this stage.

\section{Su-style furniture woodcarvings in Ming and Qing paintings}

\subsection{Su-style furniture woodcarving in the Ming and Qing engraved illustrations}

From the existing painting relics of the Ming and Qing dynasties, the woodcarvings of Su-style furniture are mainly concentrated in the Suzhou version of engraved illustrations of literary works such as novels, legends, and operas. The furniture and other objects in these illustrations help to deepen readers' understanding of words and plots, and more intuitively show the social background of the times described in the works, also point out the place, characters and scenes of the story [2].

Su-style furniture is often seen in illustrations of printed books in Suzhou in the Ming and Qing dynasties. In the woodcut illustration of "Journey to the West" in Wanli of the Ming Dynasty, a nanguan hat chair is placed on the stage, and the central part of the threesection backrest panel is carved with a ruyi pattern. The chair is also equipped with a footrest. In addition, Sustyle woodcarving furniture as a theme element is widely used in moonlight-style Suzhou opera illustrations. Taking Qing Shunzhi's carved illustration of "Feng Qiuhuang" as an example, Su-style furniture appeared in a circular illustration space, breaking the limitation of the first two square compositions. Three combed rose chairs, three people, a bonsai and a fan constitute the story scene. As can be seen from these engraved illustrations of Suzhou in the late Ming and early Qing dynasties, the images of Su-style woodcarving furniture during this period, like the real woodcarving furniture, present a beautiful and exquisite style, which is unique and visual. The regional characteristics are deeply affected by the humanities and geographical factors of Suzhou [3].

\subsection{Su-style furniture woodcarving in court paintings of the Qing Dynasty}

In addition to the black and white illustrations of the above-mentioned books, woodcarvings of Su-style furniture in the Ming and Qing dynasties have not yet been seen in color book illustrations. Painted Su-style furniture woodcarvings are very rare in Ming Dynasty paintings, and appear more in Qing Dynasty palace paintings. The "Yan Li Yi Qing" atlas, as a treasure collected by the Qing Palace, has a panoramic display of the home life of the high society in the Qing Dynasty, especially the detailed description of the furnishings. The seventh picture depicts a flat-headed table set against a wall in the flower hall. The teeth of the table are exquisitely carved with dragons and round feet. It is very similar to the Qing Dynasty Su-style beech flat case recorded in the book "Tiangong Shenyun Ming and Qing Su-style Furniture Collection". The male owner is painting a fan in the ninth picture of the album. The painting case is made of open-cut carved zigzag teeth, and the foot is a square horseshoe which is a typical Sustyle furniture in the Qing Dynasty. From the abovementioned examples of furnitures, you can see that the Ming and Qing style carved furniture was popular among the nobles of the Qing Dynasty. These pieces of furniture are extremely sophisticated. Most of them have exquisite carving decoration, and the furniture of different shapes are staggered. The combination of furniture, characters, and environment is also very coordinated, creating a unique space and elegant atmosphere of the royal family in the Qing Dynasty. The delicate depiction of the Qing court's furnishings can also be found in the fine-painted figure painting "Prince Yong Yong's Twelve Beauties" created by court painters in the early Qing Dynasty.

\section{The image of Su-style furniture woodcarving tools in graphic design of Qing Dynasty}

As early as the Song Dynasty, the basic shapes and functions of Chinese furniture were relatively complete and mature. In the Ming Dynasty, with the improvement of woodworking tools including sculpting tools and the use of hardwood, it became possible for Chinese hardwood furniture art to reach its peak. The furniture woodcarvings of different regions in the Qing Dynasty were technically similar, so the shapes of some carving tools such as chisels, saws, and files were also very similar. The furniture woodcarving tool image appearing in the image data needs to be accurately judged as being used by a specific furniture genre according to the information of the age, place of production, and author of the image.

Cigarette cards is one of the earliest imported products introduced to China at the end of the 19th century. It is a small cardboard picture attached to various colored cigarette cases. Usually, the front side is printed with pictures of various subjects, and the back is printed with cigarette advertisements and brand logos. It has certain historical value for the study of folk daily life in the late Qing Dynasty [4]. Included in the "Old Knife" brand cigarettes, "Sculpture Carver", reproduces the work scene of a carver in Shanghai and neighboring Suzhou in the late Qing Dynasty as shown in Figure 3. On the left side of the picture, a person bows his head and concentrates on using a carving knife. A person 
standing next to him is examining the drawn pattern, and a carved figure on the right is engraving the carved wooden pattern. In addition, the "Business Photo Carving Carpenter" serialized on page eighty-fourth of "Picture Daily" can be described as the epitome of the work of furniture carpenters in old Shanghai and neighboring Jiangsu and Zhejiang [5]. Using the image of woodcarver to ridicule the world, indicates that talents with real talents are rare [6].

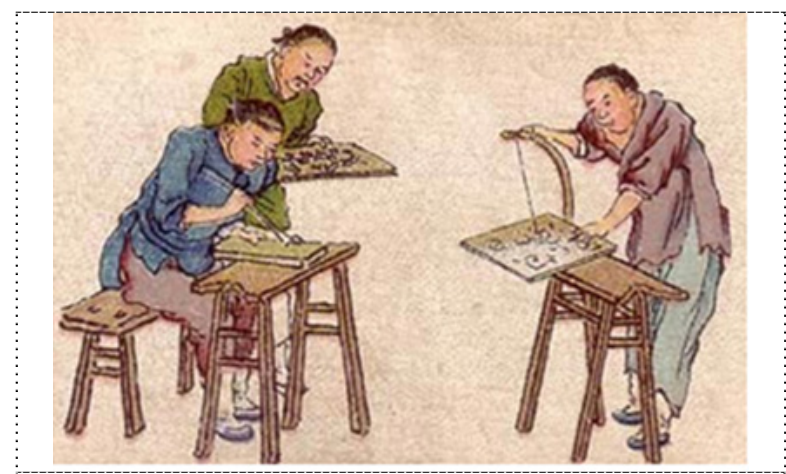

Figure 3. Wooden furniture in the shop of "Qianlong South Tour Picture Book Volume 6-Stop in Gusu"

The export paintings of the Qing Dynasty also provided a visual historical source for today's research on Su-style furniture woodcarving and carving tools of the Qing Dynasty, and complemented the reals that remain today [7]. At the end of the Qing Dynasty, the atlas entitled "The Collection of Chinese Metal Products and Crafts Tools of the Qing Dynasty" included drawings of the files, chisels and drills of Su-style furniture carving tools as shown in Figure 4. These sketched line drawing product drawings are from the hands of folk painters, and should be used as catalogue illustrations. Therefore, complicated western painting techniques have not been used to increase the real three-dimensional impression of engraving tools.

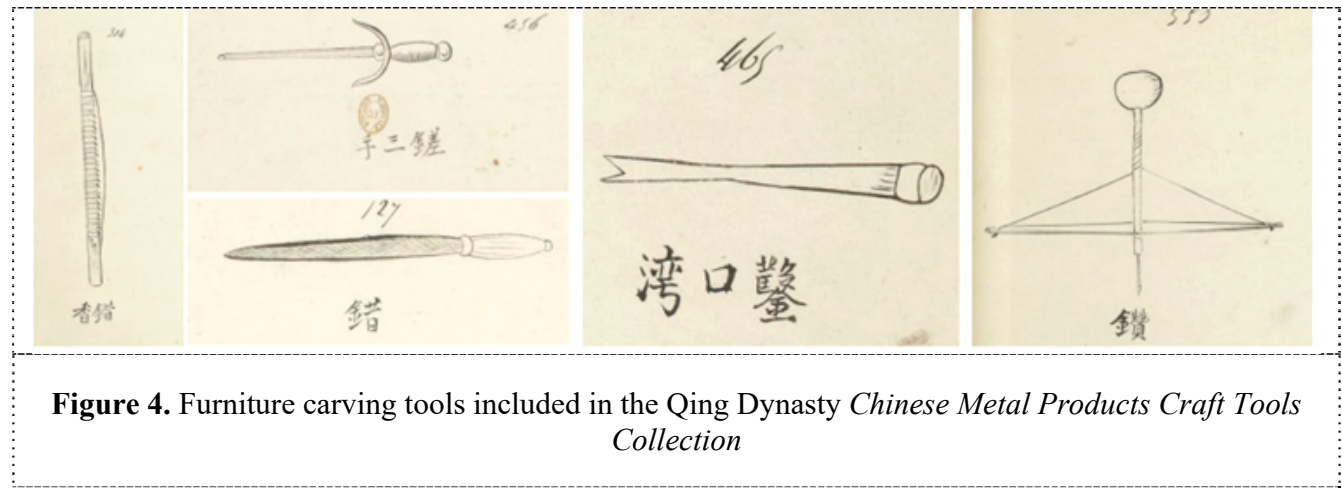

\section{Summary}

The historical materials of woodcarving images of Sustyle furniture in the Ming and Qing Dynasties were both the recorders of traditional Chinese manual craftsmanship culture, and they acted as carriers for spreading information on living culture and excellent craftsmanship with Chinese characteristics to the West in the 19th century. Through analysis, we can see the styles, decorative features, and production tools of carved furniture used by ordinary people in Suzhou in the Ming and Qing Dynasties. The images complement the existing furniture and its production tools which are important materials for studying the cultural history of Su-style furniture in the Ming and Qing dynasties.

\section{Acknowledgments}

This research was financially supported by Brand Planning and Service Design, Demonstration Course Project of Changshu Institute of Technology "Course Ideology".

\section{References}

1. $\mathrm{Hu}$ Y. (2010) Costume performance in ancient Chinese scroll figure paintings. Donghua University, Shanghai.

2. Cheng G.F. (2009) On the Function of Popular Novels in Ming Dynasty. Literature Review, 3:132138.

3. Du D. (2007) Design style of engraved illustrations of Suzhou edition in Ming Dynasty. Journal of 
Donghua University Social Science Edition, 7: 273276.

4. Long Y. (2011) The big thousand worlds in Cigarette cases: a preliminary study of the advertising art of smoke painting in the Last Century. Hunan Normal University, 2011, Changsha.

5. Feng J.N. (1999) "Picture Daily"-An important variety of stone print pictorial in the Late Qing Dynasty. Library Journal, 10: 37.

6. The Global News Agency (2010). Picture 2 Daily [M]. Shanghai: Shanghai Ancient Books Publishing House, 1999.

7. Wang $\mathrm{Ha}$ (2015). The social picture of the late Qing dynasty in export paintings. Yi Yuan, 2: 42-45. 